\title{
Flood mitigation analysis for abnormal flood
}

\author{
C. Choi, J. Ahn \& J. Yi \\ Department of Civil \& Transportation Engineering, \\ Ajou University, South Korea
}

\begin{abstract}
Rainfall characteristics are changing due to climate change in Korea, as they are across the rest of the world. While the average annual rainfall is increasing, the number of rainy days is decreasing and that results in the increase of rainfall intensity. Because of the increase in rainfall intensity, the frequency of abnormal rainfall and floods is also increasing and can lead to extensive damage. It is necessary to establish reasonable alternatives to mitigate flood damage. In order to establish suitable disaster mitigation alternatives to overcome abnormal flooding, the following methods are used. Firstly, a test basin which has a big city in downstream vulnerable to flood damage is selected. Secondly, flood vulnerability is evaluated by a variety of scenarios and flood mitigation alternatives. Finally, the goal is to find out the best flood mitigation alternative that can protect the city located downstream. Since the Namhangang River basin selected for the test basin has only one reservoir, Chungju Reservoir, the flood control capability is relatively small considering the basin area. Therefore, in the case of flood occurrence which exceeds the flood control capacity of Chungju Reservoir, Yeoju which is located downstream of Chungju Reservoir, may have flood damage. In July of 2006, the flood was close to the design flood that actually occurred in Yeoju. The July of 2006 flood event is first analyzed, and the rainfall which is $1.2,1.3,1.4,1.5$ times greater than the actual rainfall is generated and analyzed for the safety of Yeoju. On the basis of the analyzed flood vulnerability of Chungju Reservoir, five alternatives are considered to reduce the flood damage in Yeoju. As a result, the alternative of constructing a new reservoir is found to be the most efficient alternative to mitigate the flood damage in Yeoju.
\end{abstract}

Keywords: abnormal flood, flood vulnerability, flood mitigation analysis. 


\section{Introduction}

Precipitation characteristics in Korea have changed due to global warming and climate change. In the rainy season, the frequency of localized heavy rain is becoming higher, and there are heavy snowfalls in winter. Due to these phenomena, the annual mean rainfall has increased. The number of rainy days has decreased due to droughts during the monsoon season and repeated droughts in spring or fall. The intensity of the rainfall has gradually increased. As rainfall intensity has become higher, the scale of damage from abnormal floods has risen. The amount of damage from floods and the recovery periods have continued to increase, and enormous financial losses have occurred. In particular, losses in the 2000s have sharply increased in comparison with the 1980s and 1990s [10] (Table 1). In addition, since most rivers have short runoff duration due to the topography of Korea, which has many mountains, cities located at the lower reaches of rivers are exposed to damage from floods or drought. According to the UNDP [9], the Flood Risk Index (FRI) of Korea is 6.85, which is higher than that of Japan (2.81) and the U.S. (2.28) (Table 2). Thus, it is deemed that research into decreasing the flood risk should be performed by establishing countermeasures for disaster prevention that are appropriate for the reality of Korea considering the domestic flood risk.

Table 1: Damage, recovery, casualties caused by natural disaster in the country.

\begin{tabular}{|c|c|c|c|c|c|}
\hline & $\begin{array}{c}\text { Damage } \\
\text { (billion \$) }\end{array}$ & $\begin{array}{c}\text { Recovery } \\
\text { (billion \$) }\end{array}$ & $\begin{array}{c}\text { Food Control } \\
\text { Investment } \\
\text { (billion \$) }\end{array}$ & $\begin{array}{c}\text { Casualties } \\
\text { (person) }\end{array}$ & $\begin{array}{c}\text { GDP } \\
\text { (billion \$) }\end{array}$ \\
\hline \hline $1980 \mathrm{~s}$ & $2,579.8$ & $2,316.5$ & 429.0 & 2,850 & $873,055.0$ \\
\hline $1990 \mathrm{~s}$ & $5,189.8$ & $7,565.2$ & $2,182.4$ & 1,424 & $3,653,279.2$ \\
\hline $2000 \mathrm{~s}$ & $14,593.9$ & $23,724.8$ & $7,217.1$ & 678 & $5,047,666.6$ \\
\hline Total & $22,363.5$ & $33,606.5$ & $9,828.6$ & 4,952 & $9,574,000.8$ \\
\hline
\end{tabular}

Table 2: $\quad$ Flood risk index.

\begin{tabular}{|c|c|c|c|c|c|c|c|}
\hline & KOR & U.S & JAP & U.K & GER & CAN & SWE \\
\hline \hline Flood risk index & 6.85 & 2.28 & 2.81 & 0.23 & 0.25 & 2.31 & 0.61 \\
\hline
\end{tabular}

Research regarding methods for decreasing the damage resulting from floods has continued. Pilgrim and Robinson [8] reassessed the policy of decreasing flood risk by focusing on structural countermeasures. In addition, Faisal et al. [4] presented that structural countermeasures contributed tremendously to a decrease in flood damage. Al-Weshah and El-Khoury [1], Jaffe and Sanders [5], and Liaw et al. [6] researched into proposals for structural countermeasures such as structures against flood attacks installed in river basins, a drop in the peak water level using levee breaks, and a decrease in flow velocity using bank revetment as 
methods for decreasing flood damage. Birkland et al. [2] analyzed previous cases of countermeasures for decreasing flood damage, focusing on structural countermeasures in the U.S., and researched policies for the prevention of flood damage and environmentally-friendly policies. Brody et al. [3] researched nonstructural countermeasures based on cases using policies for decreasing floods performed in Florida, USA.

In this paper, in order to establish countermeasures for disaster prevention in abnormal and extreme flood situations, firstly, a test river basin for the study was selected. The most suitable for the study were those where damage can be done to cities located at the lower reaches of the rivers due to release from large structures built to resist floods in abnormal or extreme situations, such as dams. Secondly, scenarios about the abnormal or extreme floods that occur in the selected model areas were drawn up in order to assess the weaknesses to the floods in each scenario. Thirdly, diverse countermeasures for disaster prevention were taken in the test basins, and the disaster decrease effects and capabilities of the countermeasures were analyzed. Lastly, appropriate reform recommendations for disaster prevention were conceived based on the analyzed capabilities of the disaster prevention methods.

\section{Selection of the test basins}

The typical countermeasure for flood mitigation in Korea is to use the flood control capabilities of the dams built in each basin. Rainfall and the frequency of abnormal floods have increased; thus, it might be expected that floods in the downstream of the dams may not be prevented by the flood control capability of current dam. Thus, in this paper, the Namhangang River basin was finally selected as the test basin. The reason for this was that damage to the cities located in the lower reaches of rivers may occur due to the release from large structures when an abnormal flood occurs and thus, countermeasures for flood decreasing linked with dams can be considered at the basin. Since the Namhangang River basin has only one structure for flood control in comparison to its large area, it is exposed to flood risk. Thus, a weakness for flooding was evaluated from the lower reaches of the river, and countermeasures for disaster prevention that are applicable when an abnormal flood occurs, were established.

Namhangang River is located in the middle of Korea, and rises in Geomryongso, Taebaek-si, Gangwon-do. It joins the tributaries of Pyeongchanggang River, Dalcheon River, Seongang River, Cheongmicheon River, and Bokhacheon River, and forms a basin with an area of 23,800 $\mathrm{km}^{2}$. The river joins the Bukhangang River and forms the main stream of Han River. It passes through Seoul, the capital city of Korea and flows into the Yellow Sea. Chungju Reservoir, with the second-largest storage capacity of 2.75 billion $\mathrm{m}^{3}$ in Korea, is located in the main stream of Namhangang River. Hoengseong Reservoir and Geosan Reservoir are located on Seomgang River and Dalcheon River, which are the tributaries of the Namhangang River, respectively. Since the reservoirs have relatively small capacity, most of the flood volume is controlled by Chungju Reservoir. 


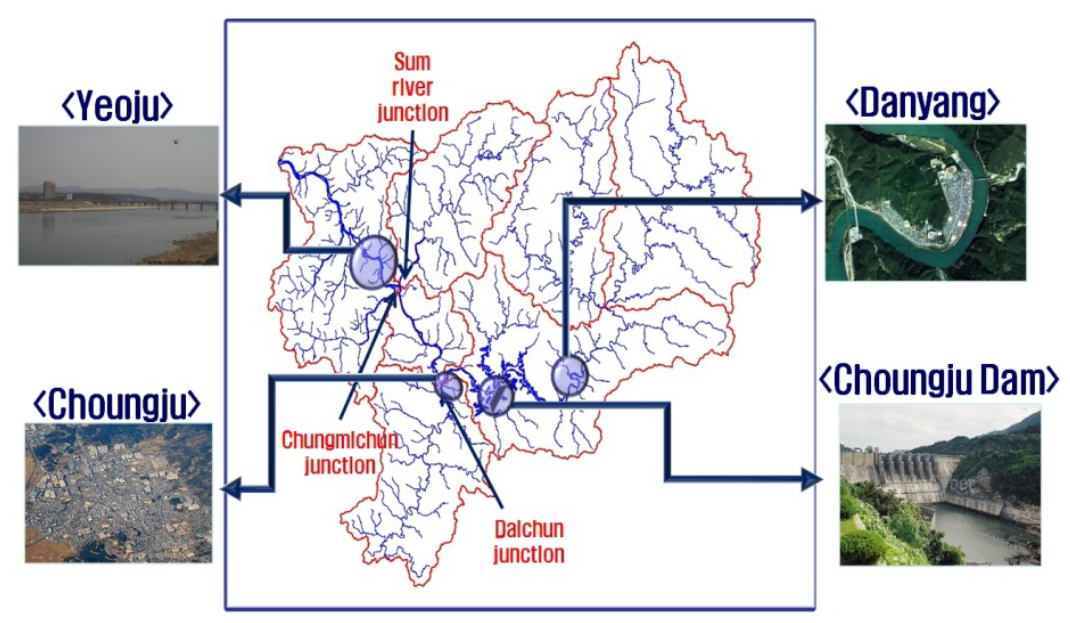

Figure 1: $\quad$ Basin map of Namhangang River.

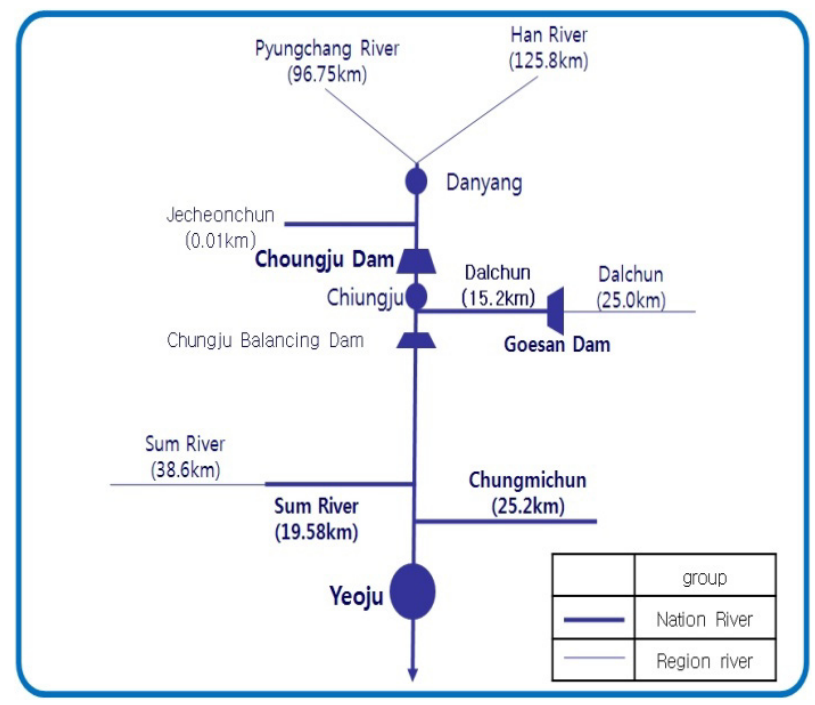

Figure 2: $\quad$ Schematic diagram of Namhangang River.

Chungju Reservoir is about $130 \mathrm{~km}$ away from Seoul. It is a multi-purpose reservoir with a basin area of about $6,650 \mathrm{~km}^{2}$ and a 2.75 billion $\mathrm{m}^{3}$ storage capacity, and controls floods and supplies 3.38 billion $\mathrm{m}^{3}$ for diverse kinds of purposes on an annual basis. The specifications of Chungju Reservoir are shown in Table 3.

In this paper, the weaknesses of the downstream reaches of the Chungju Reservoir, which have the possibility of damage by floods due to the release from the reservoir, were analyzed. Chungju and Yeoju located downstream from 
Table 3: $\quad$ Specification of Chungju Reservoir.

\begin{tabular}{|c|c|c|c|c|c|}
\hline & unit & specification & & unit & specification \\
\hline \hline basin area & $\mathrm{km}^{2}$ & 6,648 & top of the dam & EL.m & 147.5 \\
\hline total storage & $10^{6} \mathrm{~m}^{3}$ & 2,750 & design flood level & EL.m & 145.0 \\
\hline effective storage & $10^{6} \mathrm{~m}^{3}$ & 1,789 & normal water level & EL.m & 141.0 \\
\hline flood control storage & $10^{6} \mathrm{~m}^{3}$ & 616 & ruling water level & EL.m & 138.0 \\
\hline low water storage & $10^{6} \mathrm{~m}^{3}$ & 596 & low water level & EL.m & 110.0 \\
\hline
\end{tabular}

Chungju Reservoir has a history of damage from the overflow of the tributaries, depending on the release from the reservoir. Examples of tributaries entering the downstream of Chungju Reservoir include Dalcheon River, Cheongmicheon River, and Seomgang River. In this paper, the release from Chungju Reservoir and the inflow of three tributaries were used in order to calculate the flow rate at Yeoju, the downstream of Namhangang River.

\section{Abnormal flood scenarios}

\subsection{The selection of a reference scenario}

In order to draw up the scenario of an abnormal flood to evaluate weaknesses for floods in the Namhangang River basin, rainfall events that occurred in July 2006 was selected as a reference scenario. In the flood season of 2006, heavy rainfall continued to occur for a long period of time, as follows: Typhoon Ewiniar from July 8 to July 10, Typhoon Bilis from July 11 to July 13, rainy season from July 14 to July 21, and Typhoon Ant from July 25 to July 29 again. The maximum cumulative rainfall of the Chungju Reservoir basin for the month of July was measured to be $1,097 \mathrm{~mm}$ by the Bangrim rainfall gauging station. The mean rainfall in the Chungju Reservoir basin was calculated by averaging data from 33 rainfall gauging stations using Thiessen's weighting method. The mean rainfall of the basin, measured from July 14, 2006 to July 19, 2006 was 248mm (Fig. 3). At that time, the peak discharge at Yeoju was $12,199 \mathrm{~m}^{3} / \mathrm{s}$, and was close to $15,600 \mathrm{~m}^{3} / \mathrm{s}$, the design flood of Yeoju (Fig. 4). As a result of performing frequency analysis on the inflow of Chungju Reservoir and the discharge at Yeoju [7] (Tables 4 and 5), the inflow of Chungju Reservoir turned out to correspond to a frequency of approximately 500 years and the discharge at Yeoju corresponded to that of less than 50 years, according to the reference scenario.

In order to draw up a scenario for abnormal floods based on the rainfall events that occurred in July 2006, the reference scenario, a parameter was estimated to trace floods in the Chungju Reservoir basin based on the measured reservoir inflow. The HEC-HMS simulation model was used, and the Chungju Reservoir basin was simulated as a single basin to estimate a parameter meeting the peak inflow and flow type (Fig. 5). The parameter was verified by comparing with the rainfall events occurring in September 2003 (Table 6). 
112 Flood Recovery, Innovation and Response II

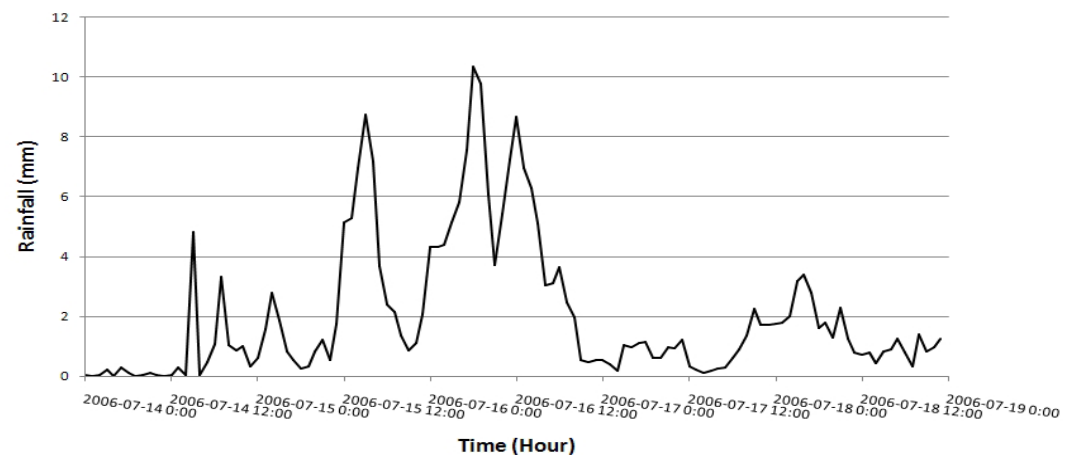

Figure 3: The mean rainfall of the basin.

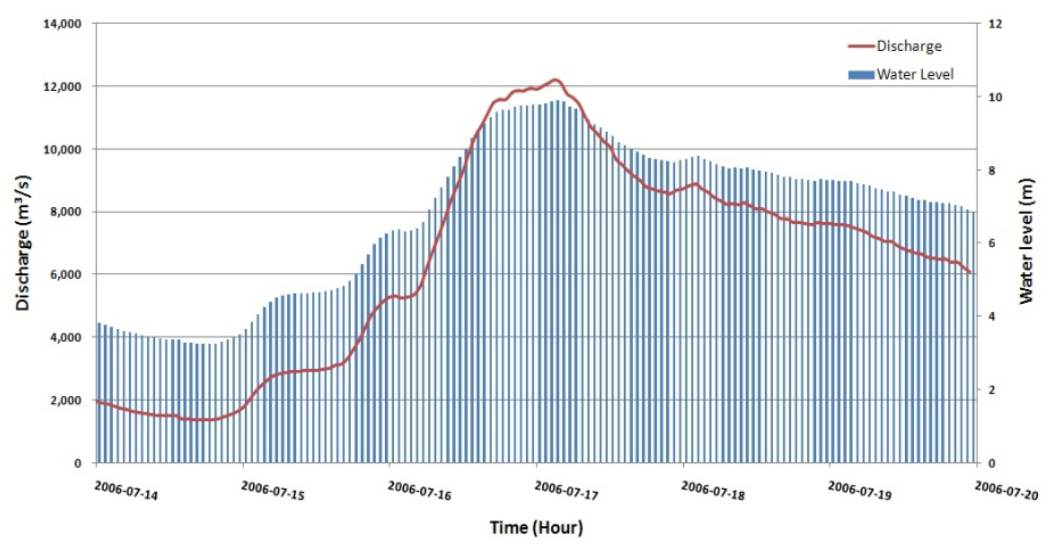

Figure 4: Discharge and water level at Yeoju.

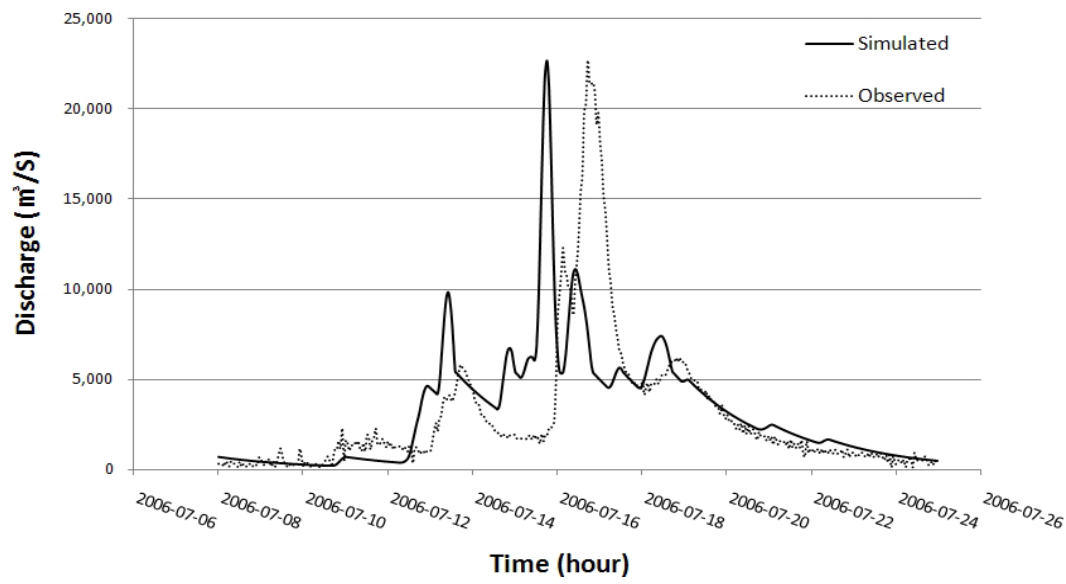

Figure 5: Simulated and observed inflow at Chungju Reservoir. 
Table 4: $\quad$ Frequency inflow at Chungju Reservoir.

\begin{tabular}{|c|c|c|c|c|c|c|c|}
\hline Frequency & 2 year & 3 year & 5 year & 10 year & 20 year & 30 year & 50 year \\
\hline Inflow $\left(\mathrm{m}^{3} / \mathrm{s}\right)$ & 5,290 & 6,894 & 8,681 & 10,925 & 13,079 & 14,317 & 15,866 \\
\hline \hline Frequency & 70 year & 80 year & 100 year & 150 year & 200 year & 300 year & 500 year \\
\hline Inflow $\left(\mathrm{m}^{3} / \mathrm{s}\right)$ & 16,881 & 17,283 & 17,954 & 19,172 & 20,035 & 21,251 & 22,781 \\
\hline
\end{tabular}

Table 5: $\quad$ Frequency discharge at Yeoju.

\begin{tabular}{|c|c|c|c|c|c|}
\hline Frequency & 50 year & 80 year & 100 year & 150 year & $200 y e a r$ \\
\hline \hline Discharge $\left(\mathrm{m}^{3} / \mathrm{s}\right)$ & 15,500 & 17,000 & 17,700 & 19,200 & 20,100 \\
\hline
\end{tabular}

Table 6: $\quad$ Estimated parameters.

\begin{tabular}{|c|c|c|c|c|c|c|}
\hline $\begin{array}{c}\mathrm{Tc} \\
(\mathrm{hr})\end{array}$ & $\begin{array}{c}\mathrm{K} \\
(\mathrm{hr})\end{array}$ & $\begin{array}{c}\text { Initial Base } \\
\text { Flow }\left(\mathrm{m}^{3} \mathrm{~s}\right)\end{array}$ & $\begin{array}{c}\text { Threshold Q } \\
\left(\mathrm{m}^{3} / \mathrm{s}\right)\end{array}$ & $\begin{array}{c}\text { Recession } \\
\text { Constant }\end{array}$ & $\mathrm{CN}$ & $\begin{array}{c}\text { Initial } \\
\text { Loss }\end{array}$ \\
\hline \hline 8.132 & 2.262 & 690.32 & 5428.8 & 0.6132 & 84.15 & 9.58 \\
\hline
\end{tabular}

\subsection{Drawing up a scenario for abnormal flood}

In order to evaluate the weakness for floods in the Namhangang River basin, the scenario for abnormal floods was drawn up using cases when rainfall occurred at $120 \%$ to $150 \%$ of the rainfall events in July 2006, which are the reference scenario. Floods were traced by using the estimated parameter for the Chungju Reservoir basin when rainfall occurred based on the scenario of abnormal floods (Table 7). The inflow of tributaries was used by multiplying the ratio in each scenario by the inflow.

Table 7: $\quad$ Calculated peak inflow based on each scenario.

\begin{tabular}{|c|c|c|}
\hline & peak inflow $\left(\mathrm{m}^{3} / \mathrm{S}\right)$ & ratio(\%) \\
\hline \hline observed value & 22,650 & 0.01 \\
\hline $100 \%$ & 22,652 & 18.10 \\
\hline $120 \%$ & 26,749 & 27.15 \\
\hline $130 \%$ & 28,798 & 36.18 \\
\hline $140 \%$ & 30,844 & 45.37 \\
\hline $150 \%$ & 32,927 & \\
\hline
\end{tabular}




\subsection{Simulated operation of the reservoir}

The simulated operation of Chungju Reservoir was performed based on its calculated inflow. HEC-5 was used for this simulation, and the reservoir was set to be operated so that the discharge to Yeoju in the reference scenario could be close to the one occurred in 2006. As a result, it was found that the discharge at Yeoju was larger than the design flood in the case of $140 \%$ rainfall scenario (Figures 6 and 7; Table 8). The flood control capabilities of Chungju Reservoir are expected to reach their limitations when a rainfall exceeds $140 \%$ of the reference scenario.

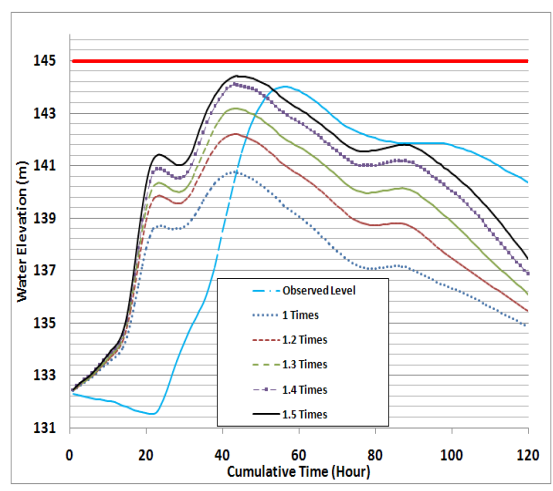

Figure 6: Water surface level of Chungju Reservoir.

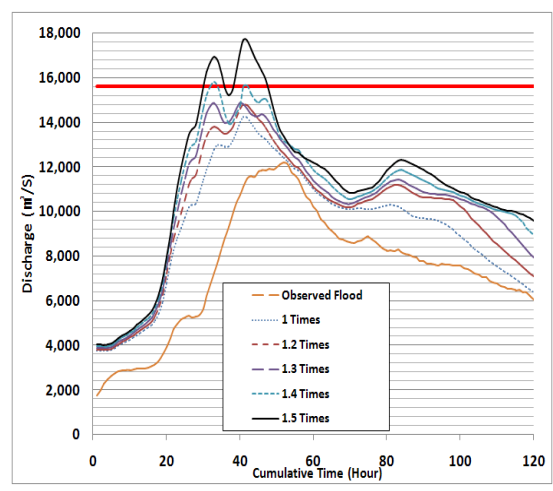

Figure 7: Discharge at Yeoju.

Table 8: $\quad$ Simulation results.

\begin{tabular}{|c|c|c|c|c|c|}
\hline & \multicolumn{2}{|c|}{ Chungju Reservoir } & \multicolumn{2}{|c|}{ Yeoju } \\
\hline & & $\begin{array}{l}\text { maximum water } \\
\text { level (EL.m) }\end{array}$ & $\begin{array}{l}\text { margin of level } \\
(\mathrm{m})\end{array}$ & $\begin{array}{c}\operatorname{maximum} \\
\text { discharge } \\
\left(\mathrm{m}^{3} \mathrm{~s}\right)\end{array}$ & $\begin{array}{c}\text { margin of } \\
\text { discharge } \\
\left(\mathrm{m}^{3} \mathrm{~s}\right)\end{array}$ \\
\hline \multicolumn{2}{|c|}{$\begin{array}{l}\text { design food level / } \\
\text { flood discharge }\end{array}$} & 145 & - & 15,600 & - \\
\hline \multicolumn{2}{|c|}{ observed value } & 144.01 & 0.99 & 12,199 & 3,401 \\
\hline \multirow{5}{*}{ scenario } & $100 \%$ & 140.76 & 4.24 & 14,249 & 1,351 \\
\hline & $120 \%$ & 142.21 & 2.79 & 14,797 & 803 \\
\hline & $130 \%$ & 143.18 & 1.82 & 14,876 & 724 \\
\hline & $140 \%$ & 144.09 & 0.91 & 15,804 & -204 \\
\hline & $150 \%$ & 144.41 & 0.59 & 17,692 & $-2,092$ \\
\hline
\end{tabular}

(Margin of level: design food level - maximum water level, margin of discharge: design flood discharge-maximum discharge.) 


\section{Comparison of the countermeasures for flood mitigation}

Research was carried out focusing on the Probable Maximum Flood (PMF) in order to consider the countermeasures for flood mitigation in the model basin and to compare the effects of flood control methods and countermeasures. In this paper, the construction of a new reservoir or a flood control reservoir which has the storage only in flood season, an off-side channel storage or a levee break in the event of an abnormal flood was considered as structural alternatives for flood mitigation. As a non-structural alternative, using a variable restricted water level for the operation of Chungju Reservoir during the flood season was considered. In order to analyze the flood control effects based on the countermeasures, channel routing was performed for tributary inflow and the release of Chungju Reservoir. In addition, GIS data was used to calculate the flooded area of downtown Yeoju and Chungju by performing a flood simulation.

Table 9 shows the flooded area of the main locations (Yeoju and Chungju). As a simulation was performed for the PMF, high values of the flooded area were calculated overall even if countermeasures for disaster prevention were applied. The off-side channel storage, flood control reservoir, and levee break among the structural alternatives resulted in inundation areas of 23 to $25 \%$ of the Yeoju area and 16 to $17 \%$ of the Chungju area. When a variable restricted water level was applied, 25 to $37 \%$ of the Yeoju area and 16 to $17 \%$ of the Chungju area were flooded. In comparison to these results, a newly-built reservoir resulted in only $7.3 \%$ of the flood area in Yeoju and $13.84 \%$ of the flood area in Chungju. In conclusion, the construction of a new reservoir gave the highest flood control effect of the countermeasures for flood decreases conceived in this paper.

Table 9: $\quad$ Flooded area at main locations caused by PMF.

\begin{tabular}{|c|c|c|c|c|c|}
\hline \multirow{2}{*}{} & \multicolumn{2}{c|}{ Yeoju } & \multicolumn{2}{c|}{ Chungju } \\
\cline { 2 - 6 } & $\begin{array}{c}\text { inundation } \\
\text { area }\left(\mathrm{m}^{2}\right)\end{array}$ & rate $(\%)$ & $\begin{array}{c}\text { inundation } \\
\text { area }\left(\mathrm{m}^{2}\right)\end{array}$ & rate (\%) \\
\hline \multicolumn{2}{|c|}{ total area } & $1,390,613$ & - & $11,642,174$ & - \\
\hline \multicolumn{2}{|c|}{120 EL.m } & 566,684 & 40.75 & $2,011,933$ & 17.28 \\
\hline \multirow{2}{*}{$\begin{array}{c}\text { change of } \\
\text { flood control } \\
\text { level }\end{array}$} & 119 EL.m & 520,257 & 37.41 & $1,991,183$ & 17.10 \\
\cline { 2 - 6 } & 118 EL.m & 371,305 & 26.70 & $1,968,786$ & 16.91 \\
\cline { 2 - 6 } & 117 EL.m & 356,322 & 25.62 & $1,952,145$ & 16.76 \\
\hline \multicolumn{2}{|c|}{ new reservoir } & 348,096 & 25.03 & $1,945,238$ & 16.71 \\
\hline \multicolumn{2}{|c|}{ off-side channel storage } & 351,460 & 7.30 & $1,611,090$ & 13.84 \\
\hline \multicolumn{2}{|c|}{ flood control reservoir } & 323,785 & 23.28 & $1,913,802$ & 16.44 \\
\hline \multicolumn{2}{|c|}{ levee break } & 355,608 & 25.57 & $2,011,933$ & 17.28 \\
\hline
\end{tabular}




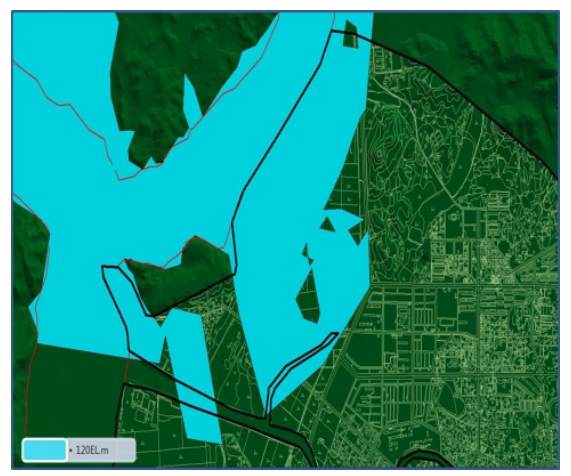

(a) Inundation Map of Chungju

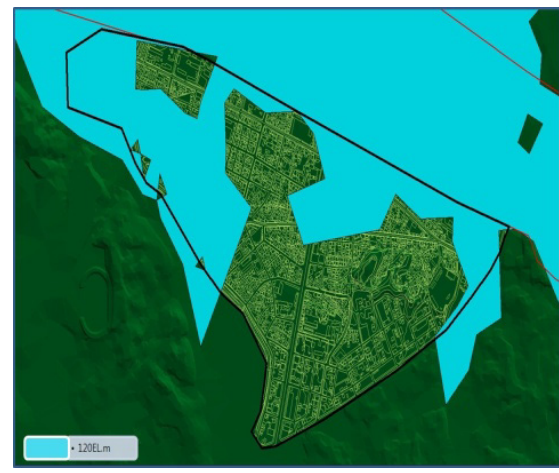

(c) Inundation Map of Yeoju

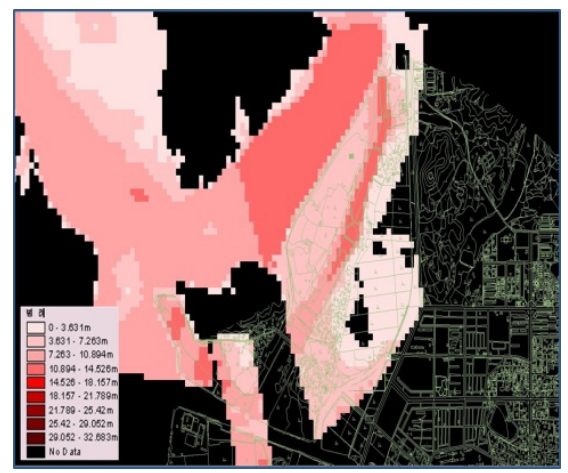

(b) Inundation Depth of Chungju

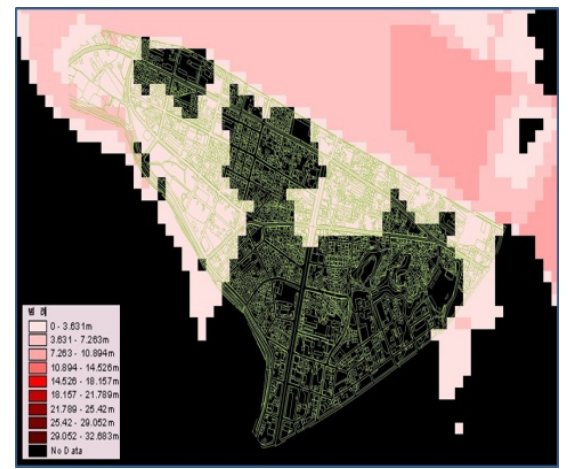

(d) Inundation Depth of Yeoju

Figure 8: $\quad$ Flooded area and inundation depth without disaster prevention.

Figures 8(a) to 8(d) show the flood inundation area and inundation depth of Chungju and Yeoju under the PMF condition when countermeasures for disaster prevention are not taken. Figures 9 (a) to 9(d) illustrate the flood inundation area and inundation depth of Chungju and Yeoju when floods are controlled by the newly-built reservoir.

\section{Summary and conclusions}

In this paper, it was confirmed that damage was to be expected to occur in the Namhangang River basin when an abnormal flood occurs. This was ascertained by analyzing the abnormal floods scenarios. In addition, it is considered that the flood control capabilities of Chungju Reservoir will reach the limitations when an abnormal or extreme flood occurs. Among the countermeasures for decreasing the damage from flooding, the construction of a new reservoir, a flood control reservoir, and an off-side channel storage as well as a levee break were considered as structural alternatives. As a non-structural alternative, the adoption of a 


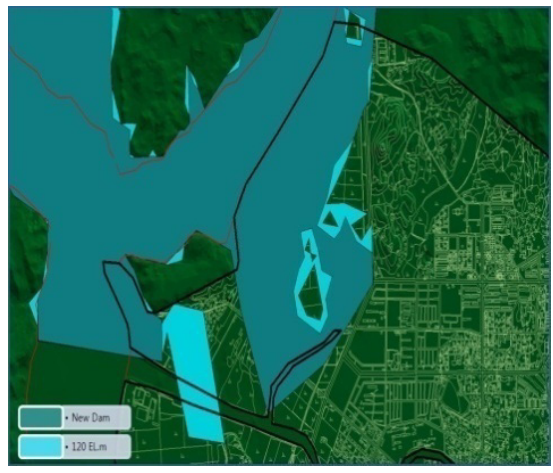

(e) Inundation map of Chungju

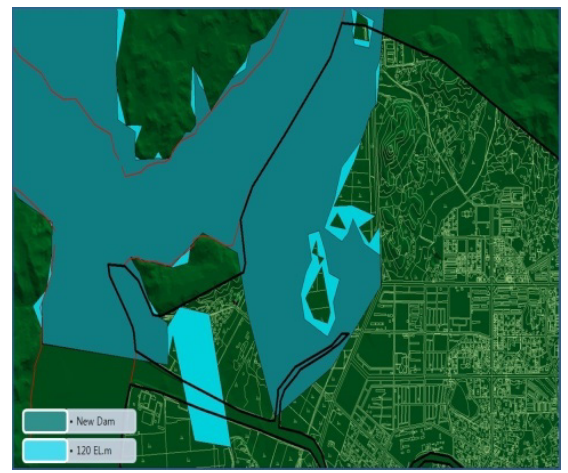

(g) Inundation Map of Yeoju

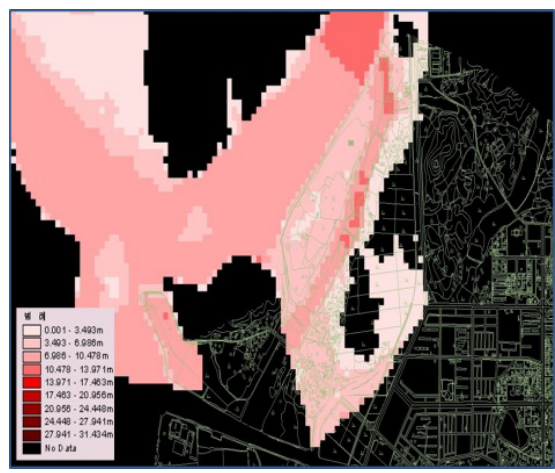

(f) Inundation Depth of Chungju

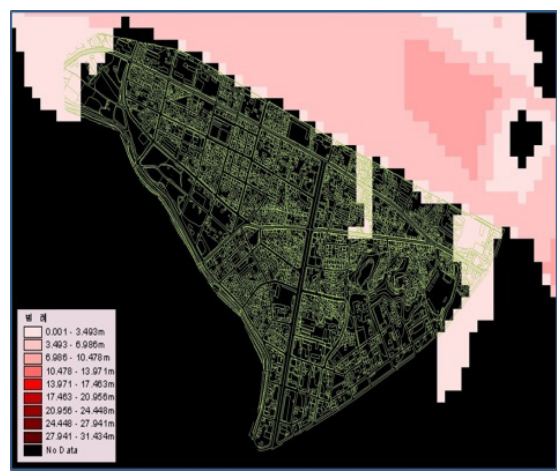

(h) Inundation Depth of Yeoju

Figure 9: $\quad$ Flooded area and inundation depth by new reservoir construction.

variable restricted water level at Chungju Reservoir was reviewed. Finally, it was concluded that the highest flood control effects were obtained when a new reservoir was built in the Chungju Reservoir basin in the event of the PMF.

\section{Acknowledgement}

This research was supported by a grant (Code\#'08 RTIP B01-01) from Regional Technology Innovation Program (RTIP) funded by the Ministry of Land Transport and Maritime affairs of the Korean government.

\section{References}

[1] Al-Weshah, R., El-Khoury, F.(2000) Flood risk mitigation using watershed management tools: Petra area (Jordan), Proceedings of the 9th United Engineering Foundation Conference on Risk-Based Decision making in 
Water Resources - Risk-Based Decision making in Water Resources IX 306, pp. 164-172

[2] Birkland, T.A., Burby, R.J., Conrad, D., Cortner, H., Michener, W.K.(2003) River ecology and flood hazard mitigation, Natural Hazards Review 4 (1), pp. 46-54

[3] Brody, S.D., Zahran, S., Highfield, W.E., Bernhardt, S.P., Vedlitz, A.(2009) Policy learning for flood mitigation: A longitudinal assessment of the community rating system in Florida, Risk Analysis 29 (6), pp. 912-929

[4] Faisal, I.M., Kabir, M.R., Nishat, A.(1999) Non-structural flood mitigation measures for Dhaka City, Urban Water 1 (2), pp. 145-153

[5] Jaffe, D.A., Sanders, B.F.(2001) Engineered Levee breaches for flood mitigation, Journal of Hydraulic Engineering 127 (6), pp. 471-479

[6] Liaw, C.-H., Tsai, Y.-L., Cheng, M.-S.(2006) Assessing flood mitigation alternatives in Shijr area in metropolitan Taipei ,Journal of the American Water Resources Association 42 (2), pp. 311-322

[7] Ministry of Land, Transport and Maritime Affairs, Namhangang River Master Plan, Korea, 2009

[8] Pilgrim, D.H., Robinson, D.K.(1979) Toward a Flood-Hazard mitigation policy for Australia, Institution of Engineers, Australia, Civil Engineering Transactions CE 21 (2), pp. 63-68

[9] UNDP, Reducing Disaster Risk, A Challenge for Development, 2004

[10] Korea Water Resources Corporation, Water Resources Basic Statistics, 2009 